\title{
Relationships of internet gaming reasons to biological indicators and risk of internet gaming addiction in Korean adolescent male game users
}

Nahyun Kim ${ }^{1}$ Mi Ja Kim², Tonda L. Hughes ${ }^{3}$, Hyeweon Kwak ${ }^{4}$ and In Deok Kong ${ }^{5^{*}}$ (D)

\begin{abstract}
Background: There are no standard diagnostic criteria or interventions for internet gaming addiction (IGA) even though IGA is one of the most pervasive public health issues among youth worldwide. Internet gaming reasons or motivations have been studied as a potential predictor of IGA, but the results have been inconsistent and biological indicators of gaming reasons have rarely been studied. We sought to (1) identify categories of internet gaming reasons, (2) examine the relationship of gaming reasons to risk of IGA, and (3) describe biological indicators associated with reasons for gaming.
\end{abstract}

Methods: We used a multi-phase cross-sectional design including individual interviews; focus group discussion; and descriptive, comparative analysis. Fifteen Korean adolescent male internet gamers participated in individual interviews and eight participated in a focus group aimed at identifying reasons for internet gaming. Using the identified gaming reasons from these sources we surveyed 225 adolescent game users using a self-report questionnaire. Participants provided blood samples for assessment of norepinephrine (NE) and serum cortisol.

Results: We identified four major categories of internet gaming reasons: entertainment, getting along with friends, stress relief, and habitual gaming. The habitual group showed significantly greater risk of IGA than the other groups $(p<.001)$ and the lowest plasma NE levels $(p=.035)$, possibly indicating an alteration in autonomic function.

Conclusion: Health care providers are encouraged to screen adolescents for excessive internet gaming and to intervene with those who report habitual gaming behaviors. When feasible, assessment of biological indicators, such as plasma NE, may help to identify youth at greatest risk of IGA.

Keywords: Addiction, Adolescent, Internet, Motivation, Norepinephrine

\section{Background}

Excessive gaming behavior has received increasing attention in society and in academia and research over the past decade. In 2013, the American Psychiatric Association (APA) included excessive gaming behavior, designated as

\footnotetext{
* Correspondence: kong@yonsei.ac.kr

${ }^{5}$ Department of Physiology, Yonsei University, Wonju College of Medicine, Wonju, Gangwon-Do 26426, Republic of Korea

Full list of author information is available at the end of the article
}

Internet Gaming Disorder (IGD), in the Fifth Edition of the Diagnostic and Statistical Manual of Mental Disorders (DSM-V) appendix as a potential mental disorder [1]. Furthermore, the World Health Organization (WHO) recently designated "Gaming Disorder" as a new diagnosis in the 11th final revision of the International Classification of Diseases (ICD-11) [2]. The diagnostic criteria for IGD and Gaming Disorder are similar because both were basically adapted from the DSM-V criteria for pathological

(c) The Author(s). 2020 Open Access This article is licensed under a Creative Commons Attribution 4.0 International License, which permits use, sharing, adaptation, distribution and reproduction in any medium or format, as long as you give appropriate credit to the original author(s) and the source, provide a link to the Creative Commons licence, and indicate if changes were made. The images or other third party material in this article are included in the article's Creative Commons licence, unless indicated otherwise in a credit line to the material. If material is not included in the article's Creative Commons licence and your intended use is not permitted by statutory regulation or exceeds the permitted use, you will need to obtain permission directly from the copyright holder. To view a copy of this licence, visit http://creativecommons.org/licenses/by/4.0/. The Creative Commons Public Domain Dedication waiver (http://creativecommons.org/publicdomain/zero/1.0/) applies to the data made available in this article, unless otherwise stated in a credit line to the data. 
gambling [1-3]. However, some controversy still exists about the inclusion of IGD in DSM-V and Gaming Disorder in ICD-11 due to lack of evidence [4-9]. Thus, more research is needed to identify clear criteria for diagnosis of IGD and/or Gaming Disorder. Regarding the terms applied to excessive gaming behavior, "addiction," "disorder," "pathological," and "problematic" have been used interchangeably to describe individuals with this condition [10-12]. We primarily use the term "internet gaming addiction," or IGA, in this paper because we believe that it is clearer and most commonly used in the research literature, including our prior studies [10-13]. IGA is defined as excessive or compulsive use of internet games that interferes with daily life; individuals with IGA tend to isolate themselves from social contact with others and to concentrate almost entirely on game activities [14].

As internet games have universally grown in popularity and IGA has become one of the most pervasive public health issues among youth worldwide [15], internet gaming motivations or reasons have been studied as one potential predictive risk factor for IGA. Understanding motivations or reasons for internet gaming is important because of their predictive and diagnostic value in identifying risk of IGA in internet game users. According to Deci and Ryan [16], game players should enjoy gaming insofar as it satisfies a player's basic psychological need; thus, each player has different motives for playing games on the internet [17-19]. Furthermore, because game motivations can predict hours spent playing games [18, 19], understanding of individual differences in motives may be crucial to predict which gamers are at risk for pathological game use [20].

Yee [19] introduced 10 motivations within three major categories for online game playing: achievement, consisting of subcomponents of advancement, mechanics, and competition; social, consisting of socializing, relationship, and teamwork; immersion, consisting of discovery, roleplaying, customization, and escapism. However, these ten motivations are diverse and often overlap [21], and the empirical results were inconsistent with regard to their relevance to risk of addiction [22]. For example, Caplan et al. [23] reported that immersion predicts problematic Internet use, whereas Zanetta Dauriat et al. [24] suggested that achievement, escapism, and socializing predict addictive gaming. In addition, Kuss et al. [22] indicated that escapism and mechanics significantly predict excessive gaming and proposed them as stronger predictors than time investment in gaming. Furthermore, other dimensions of gaming motivations have been introduced by several researchers $[18,21-23,25-29]-$ many of which overlap with those suggested by Yee [19] and do not show consistent results regarding the association of IGA to gaming motivations or reasons [30].
Therefore, although many of the reasons are likely associated with internet gaming behavior, it remains unclear which reasons are most predictive of IGA [12, 13]. Furthermore, objective measures such as biological indicators have rarely been considered in relation to gaming reasons. Although autonomic functions have been found to be associated with internet gaming behaviors [31-37] few studies have examined their associations with gaming reasons.

Hence, our study aimed to fill this gap in the literature by examining reasons for internet gaming and the relationships of gaming reasons with IGA risk and with two biological indicators--plasma norepinephrine (NE) and serum cortisol--because these compounds reflect and are representative of autonomic responses to stimuli [38-40]. Although the terms "motivations" and "reasons" have been used interchangeably for internet gaming in previous studies, we use "internet gaming reasons" in this paper to refer to both motivations and reasons for excessive gaming.

\section{Methods \\ Study design}

This study is a multi-phase cross-sectional study that included individual interviews, focus group discussions, survey questionnaire, and biological analysis. It was a part of larger study that examined the role of the autonomic nervous system in development of IGA among adolescent males [36, 41, 42]. The current study focuses on identifying categories of gaming reasons and their relationships to IGA risk and to biological indicators (NE and cortisol levels). Although IGA risk and plasma NE and cortisol levels have been assessed in our previous studies, the research question and study sample are different. For example, the current study included only adolescents who reported being currently engaged in internet gaming.

\section{Participants and procedures}

All study participants were male high school students (adolescents) who came to a regional health center in a city in South Korea in response to an advertisement about the study. Convenience and snowball sampling methods were used to recruit the sample. This study included three phases. In the first phase 15 adolescent males were interviewed individually; the second phase involved eight participants in a focus group discussion; and in the third phase 225 participants completed a questionnaire and provided a sample of blood.

Gaming reasons were generated in the first and the second phases of the study. Individual participants in the first phase were asked to describe gaming reasons. Participants in the second phase (focus group) were asked to affirm or revise/add to the gaming reasons obtained 
in the first phase. Both the individual interviews and the focus group interview were conducted in a private room, and responses were incorporated into the questionnaire used in phase three. Participants in the third phase first completed the questionnaire in a private room and then blood samples were drawn. All participants fasted for 12 $\mathrm{h}$ before blood sampling. In addition, participants were instructed not to smoke, drink caffeinated beverages, or engage in internet gaming for $24 \mathrm{~h}$ prior to data collection. This study was approved by the Institutional Review Board of a University. Informed consent was obtained from all participants and their legal guardians.

The sample size for the third phase was determined using one-way ANOVA analysis based on a medium effect size 0.25 [22, 24], an alpha level of 0.05 , and a power of 0.80 using the G-power software [43]. A minimum sample size of 180 was estimated and we determined that and a sample size of 225 should provide ample power to detect statistically significant findings. The study sample was limited to male participants because male adolescents are known to be more commonly addicted to internet gaming than are their female counterparts [44] - and because reasons for gaming may differ by gender [19]. The flowchart for sampling procedures is depicted in Fig. 1.

\section{Variables}

The variables considered for phase three of the study consisted of demographic characteristics; internet gamingrelated information, including gaming reasons; IGA risk; and biological indicators. These variables, except biological indicators, were measured using a single questionnaire. The demographic characteristic- and internet gaming-related items (excluding gaming reasons) were generated from the literature; the content validity and reliability of the gaming reason-related items were established by four content experts. Biological indicators were assayed using blood samples.

\section{Demographic characteristics}

Demographic items included participant age as well as information about smoking, drinking, and sleep time. Data related to current smoking and to alcohol consumption were obtained using yes/no responses. Sleep time was obtained using two categories; six hours or more a day and less than six hours a day.

\section{Internet gaming-related information}

Internet gaming-related information included amount of time spent on internet gaming (minutes per day) and duration of internet gaming participation (years). Participants

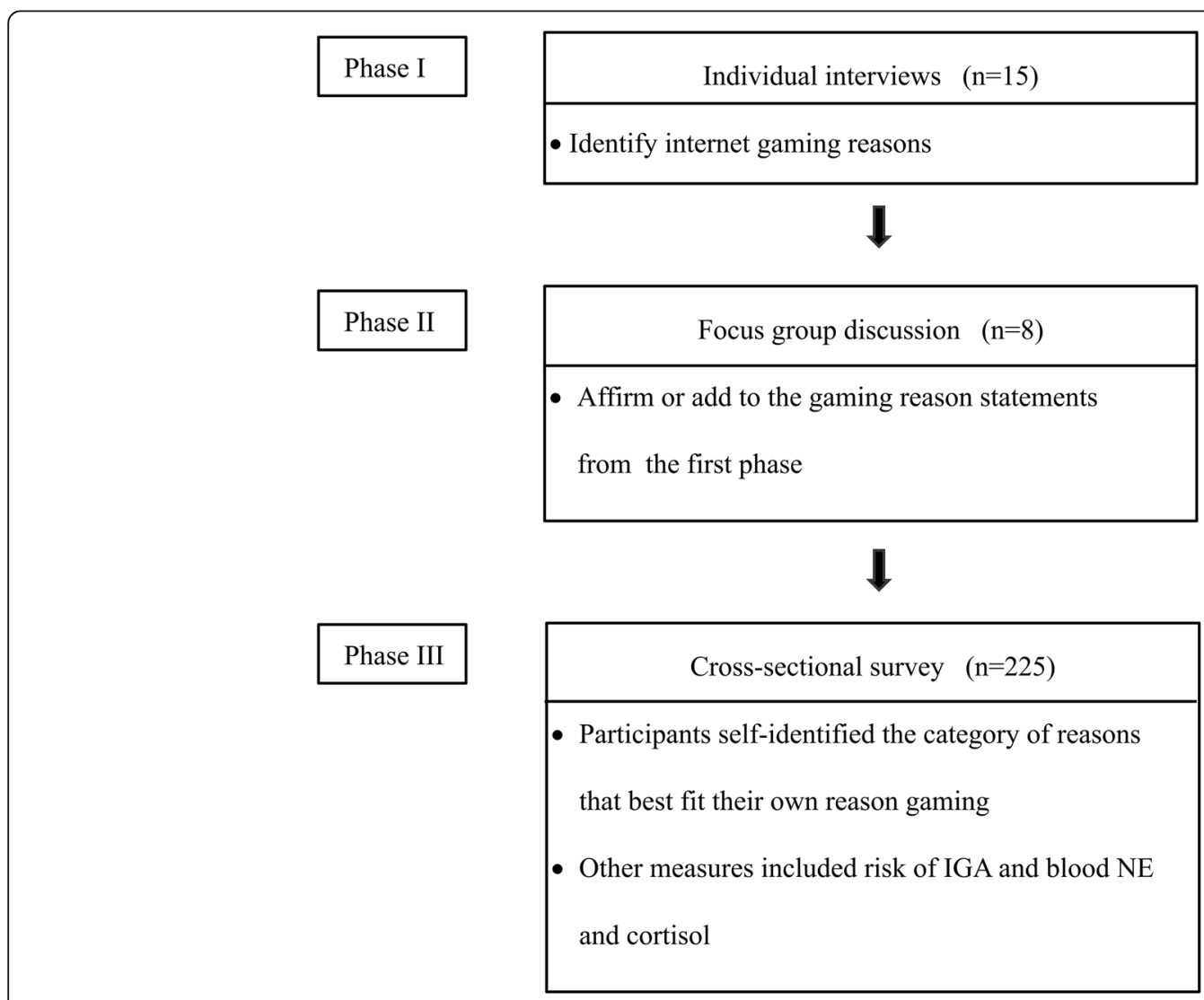

Fig. 1 Flow chart of selection process of the study participants and data collection. IGA: internet gaming addiction, NE: norepinephrine 
were asked to select one of four reasons that best described why they engaged in internet gaming. The categories included (1) entertainment, (2) getting along with friends (or friendship), (3) stress relief, and (4) habitual gaming. As described above, these categories were derived from individual interviews with 15 participants in the first phase and from the focus group interview with 8 participants in the second phase of the study. These interviews were performed by the principal investigator to identify perceived internet gaming reasons expressed in the adolescents' own words. In the first phase, individual participants were asked to describe as many gaming reasons as possible in response to the question, "Why do you play internet games?" The duration of each interview ranged from 5 to $30 \mathrm{~min}$. Overall, 36 statements were derived from the interview responses and were analyzed by two independent coders on the research team, both of whom were experienced in content analysis. In the second phase, statements derived in the first phase in were reviewed in a 45-min focus group interview in which 8 adolescents were asked about their agreement with the 36 statements and whether they could think of additional reasons for playing internet games. During the discussion participants were instructed to respond to questions by providing the first thought or feeling coming to their mind based on their own experiences and views. Participants' responses were simple and brief, e.g., "because it's fun," "to play with friends," or "just to do." The 32 statements generated from the focus group discussion were similar to those generated in the first phase. A total of 68 statements were categorized by the two independent coders of the research team initially and then validated by participants in the focus group discussion.

\section{Internet gaming addiction risk}

IGA risk was measured using the IGA scale developed by the Korean Agency for Digital Opportunity and Promotion (KADO) [45]. The KADO scale was modified from Young's Addictive Use of Internet scale [46] to assess the degree of IGA tendency in Korean adolescents. The KADO scale consists of three subscales that address game-oriented life, tolerance and loss of control, and withdrawal and affective experience [45]. This scale has been used to screen for IGA among Korean adolescents in annual national surveys. The IGA scale is a 20 -item self-report measure; each item is rated on a 4-point Likert scale ranging from $1=$ "not at all" to $4=$ "always." The total score for the scale ranges from 20 to 80, with higher overall scores indicating greater risk of IGA. According to KADO, a scale score of 49 or above indicates high risk of IGA, and a score of 38 or above indicates overuse of games and potential risk of IGA. More details on the scale items are provided elsewhere [36]. The
Cronbach's alpha for the scale in the current study was 0.945 , indicating high internal consistency.

\section{Biological indicators}

Peripheral venous blood samples for plasma NE and serum cortisol analyses were drawn from participants by professional nurses following standard laboratory procedures for assays. For each subject, $5 \mathrm{ml}(\mathrm{mL})$ of venous blood was extracted using a heparin anticoagulation vacuum tube. Levels of plasma NE were analyzed using highperformance liquid chromatography (HPLC, Agilent 1200 series, Agilent Technology, USA). Serum cortisol levels were analyzed by chemiluminescent immunoassay using ADVIA Centaur and ADVIA Centaur XP systems (ADVIA Centaur XP, Siemens, USA). The ADVIA Centaur cortisol assay is a competitive immunoassay using direct chemiluminescent technology.

\section{Statistical analysis}

Statistical analysis was performed to examine associations between reasons for gaming reasons and IGA risk and biological indicators. Data were analyzed using IBM SPSS statistics ver. 20.0 (IBM Co., Armonk, NY, USA). Descriptive statistics such as frequency, percentage, mean, and standard deviation were used to summarize the participants' demographic and internet gamingrelated characteristics. ANOVA was used to compare differences in levels of plasma NE and serum cortisol and IGA risk based on the four categories of internet gaming reasons, with Scheffe post-hoc tests. Analyses of categorical variables by the four gaming reason groups were analyzed using $x^{2}$-tests. A $p$-value of $<.05$ was considered statistically significant.

\section{Results \\ Reasons for internet gaming}

A total of 68 statements related to internet gaming reasons were grouped into four categories. Each category of reasons and related statements are summarized in Table 1. Among a total of 68 statements, 27 items (39.7\%) were categorized as entertainment and included reasons such as "there are no leisure activities to do," "playing games is fun," and "eliminating boredom;" 17 items $(25.0 \%)$ were categorized as friendship (e.g., "making friends," "maintaining friendship," and "enjoying gaming with friends"); 13 items (19.1\%) were categorized as stress relief (e.g., "getting rid of stress," "reducing tension," and "relaxing"); 11 items (16.2\%) were categorized as habitual gaming (e.g., "no other special reasons," "habitually," and "immersing myself in gaming regardless of my will"). 
Table 1 Four internet gaming reasons in male adolescents

\begin{tabular}{|c|c|c|}
\hline Categories & n (\%) & Statement summary \\
\hline Entertainment & $27(39.7)$ & $\begin{array}{l}\text { There are no leisure activities to do } \\
\text { Playing games is fun } \\
\text {. Eliminating boredom } \\
\text { Passing time } \\
\text { Playing games as a hobby } \\
\text { Relieving boring }\end{array}$ \\
\hline Friendship & $17(25.0)$ & $\begin{array}{l}\text { Making friends } \\
\text { Maintaining friendship } \\
\text { Enjoying gaming with friends } \\
\text { Being with friends. } \\
\text { Sharing consensus with friends } \\
\text {. Bonding of sympathy with friends }\end{array}$ \\
\hline Stress relief & $13(19.1)$ & $\begin{array}{l}\text { Getting rid of stress } \\
\text { Reducing tension } \\
\text {. Relaxing } \\
\text {. Forgetting something to do }\end{array}$ \\
\hline Habitual gaming & $11(16.2)$ & $\begin{array}{l}\text { No other special reasons } \\
\text { Habitually } \\
\text { Immersing myself in gaming regardless } \\
\text { of my will } \\
\text { Just to do so } \\
\text {. Being addicted without noticing }\end{array}$ \\
\hline Total & 68 (100\%) & \\
\hline
\end{tabular}

\section{Internet gaming reasons, risk of internet gaming addiction, and biological indicators}

As shown in Table 2, the mean age of the 225 participants was $16.62 \pm 1.03$ years; mean age did not significantly differ among the internet gaming reason groups. Among the four groups, the habitual gaming group showed significantly greater IGA risk than the entertainment and friendship groups in terms of IGA scores $(F=9.120$, $p<.001)$. Daily internet gaming time was also significantly longer in the habitual gaming group than in the other groups $(F=4.958, p=.002)$. Plasma NE levels were lowest in the habitual gaming group among four gaming reason groups $(F=2.909, p=.035)$. Serum cortisol levels were slightly higher in the stress relief group than in the other groups, but the differences were not statistically significant $(F=0.606, p=.612)$. Duration of internet gaming and other individual behaviors such as smoking cigarettes, drinking alcohol, and sleep time did not significantly differ among the groups.

\section{Discussion}

In this study, we identified four major groups of internet gaming reasons: entertainment, getting along with friends (or friendship), stress relief, and habitual gaming. Furthermore, we investigated whether risk of IGA and biological indicators (i.e., NE and cortisol levels) differed by reasons for gaming in male adolescent game users. Entertainment, friendship, and stress relief were reported in earlier studies as common reasons for internet gaming $[19,21,22,47]$. However, habitual gaming has not previously been reported as an internet gaming reason.

Our results partially support the hypothesis that IGA risk and biological indicators differ by gaming reason. Specifically, habitual game users showed significantly higher internet gaming time and IGA scores and lower

Table 2 Differences of internet gaming addiction risk and biological indicators according to the gaming reasons $(N=225)$

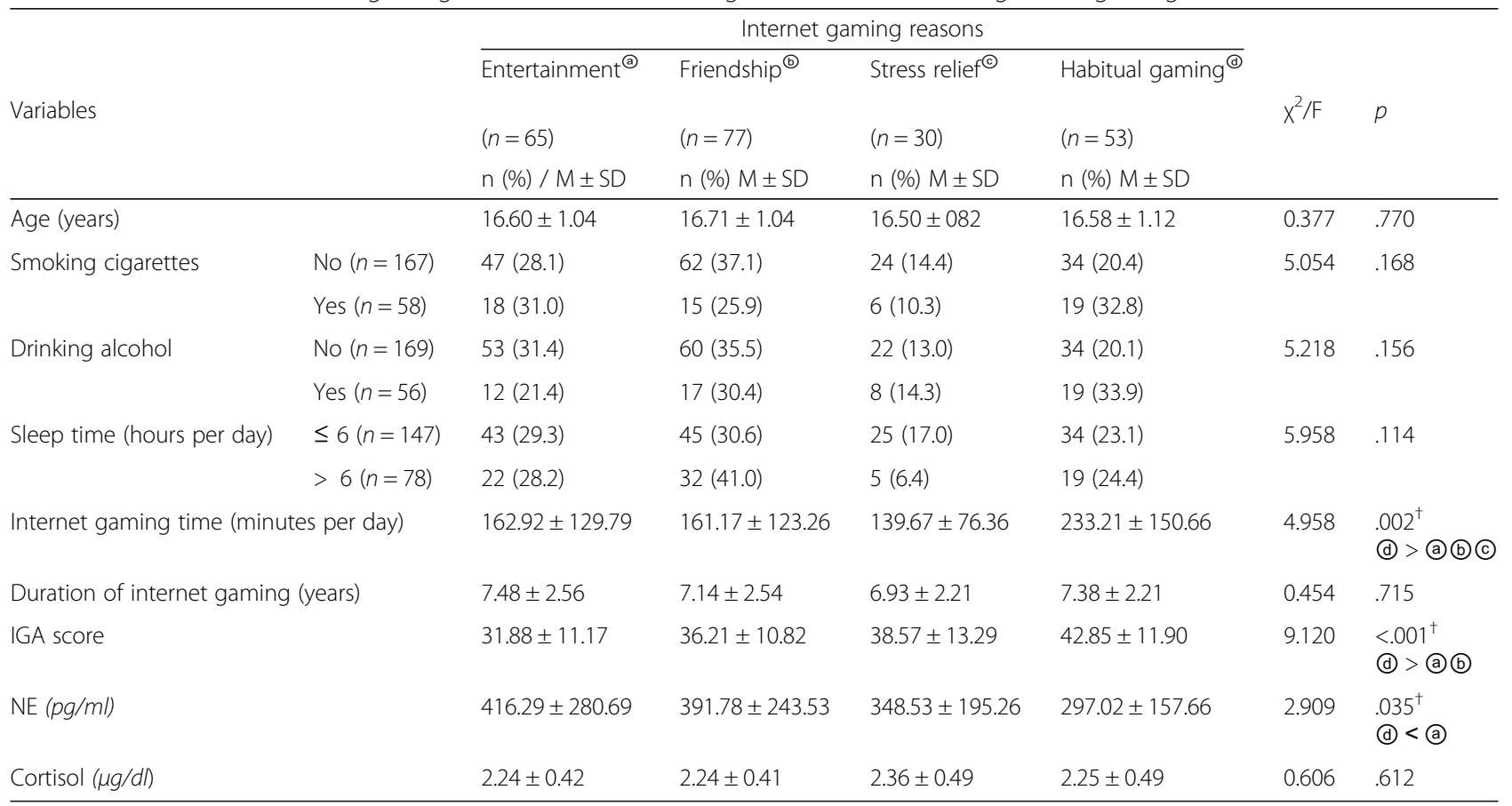

Notes: $\mathrm{n}=$ number, M: mean, SD: standard deviation, IGA: internet gaming addiction, NE: norepinephrine ${ }^{\dagger}$ Scheffe test 
NE levels than participants in the other gaming reason groups; however, no significant difference in cortisol levels was found. Instrumental behavior theory suggests that in contrast to goal-directed action, habitual control of action is characterized by involuntary, compulsive behavior $[48,49]$. Habitual control of action is one important indicator of addiction [40], and therefore, a habitual gaming pattern may be an indicator of the level of addiction risk in heavy gamers. Our results seem to be consistent with those of earlier studies of alcohol abusers. In these studies, automatically activated motivations toward alcohol-related stimuli were associated with higher levels of addictive behaviors [50, 51].

A possible mechanism supporting the association between habitual gaming and IGA is explained by instrumental behavior theory. Based on this theory, behavior directed at obtaining rewards and avoiding punishment is controlled by a goal-directed system and a habit system [48]. Initial behavioral control is mainly goaldirected, but with repetition of an action, there is a gradual shift to habitual control [52]. During early engagement in internet gaming, adolescents may have specific goals or motivations for gaming such as entertainment, socialization, or escaping from reality. Goal-directed gaming activities seem to be initiated to achieve desirable outcomes and may be reinforced by the incentive value of the rewarding outcomes [53-55]. Over time, however, actions can become more and more habitual, and eventually they can be automatically evoked by triggering stimuli or motivations regardless of the possible outcomes [55, 56]. Some studies on addiction have shown that brain activity and structure are involved in changes from goal-directed behavior to habitual behavior [57-59]. Adolescents, in particular, are more likely than adults to develop habits because their executive inhibition skills are not yet fully developed $[50,51]$. Under this line of reasoning, habitual gaming behavior would not be an initial motivation or reason for internet gaming but might be a consequence of gaming activities repeated for specific reasons. Schwabe and colleagues [40, 60-63] suggested that this transition from voluntary, goal-directed action to habitual control of action is stimulated by prolonged stress. There is strong evidence that stress and related hormones (e.g., glucocorticoid and norepinephrine) are important risk factors for development of a variety of addictions [40, 60, 61, 63, 64].

Notably, in our study, plasma NE levels were found to differ according to gaming reasons, which may support our assumption that the mechanism of habituation results from excessive internet gaming and stress-related physiological responses. Plasma NE levels were lower in the habitual gaming group than in the other groups; findings that are consistent with those of previous studies reporting associations of lower NE levels among internet addiction
[37] and IGA [36] groups. These consistent findings in our study and in previous studies suggest that lower plasma NE levels in excessive internet gamers may be involved in the development of IGA, although the mechanisms of this involvement are unclear. In psychiatry research involving plasma NE, lower levels of NE were found in substance abusers than in healthy controls [65], and the mechanism was reported to be autonomic function dysregulation $[11,36,65]$. In contrast, serum cortisol levels did not significantly differ among the four groups in our study, a finding that was inconsistent with previous study results. In fact, a wealth of studies have reported higher serum cortisol levels in addicts, including substance abusers $[41,65,66]$, due to HPA axis sensitization or blunting to stress $[64,65,67]$. However, some studies have also reported a negative association with cortisol levels, or no alterations in cortisol levels among people with pathological gambling or internet addiction $[68,69]$. Interestingly, all these findings indicate alterations to HPA axis activity [67]. Our physiological results are the first reported with regard to internet gaming reasons or motivations. However, we are unable to explain the mechanisms of the phenomena observed, as this was not a focus of our study. Further research is needed to better understand the mechanisms underlying the relationship between autonomic function and gaming reasons.

Despite notable strengths of the study, the results should be evaluated within the context of some limitations. For example, we recognize that our study may not have included all reasons for internet gaming, nor did it assess game genre. Our use of a cross-sectional design limits interpretations of temporal order and because the sample was limited to male adolescents, we are unable to generalize findings to female adolescents or other population groups. Longitudinal studies with random samples are needed that include both male and female participants of various ages. In addition, studies conducted in countries other than Korea could shed light on how cultural contexts influence gaming behaviors and IGA.

\section{Conclusions}

Our findings--that the habitual internet gaming group had the highest IGA risk and the lowest plasma NE levels--have potential implications for the clinical care of adolescent males. Health care workers can incorporate these findings in their health screenings of adolescent boys and initiate early preventive interventions with those who exhibit excessive internet game playing. Furthermore, researchers can use the information about reasons for engaging in internet gaming to further investigate the mechanisms underlying IGA. The study findings also have the potential to influence decisions about including IGA as a formal disorder in the DSM-V--a step that would encourage further research to develop 
gaming interventions for adolescents, regardless of where they live in the world.

\section{Abbreviations}

DSM-V: Diagnostic and Statistical Manual of Mental Disorders, Fifth Edition; IGA: Internet Gaming Addiction; IGD: Internet Gaming Disorder; KADO: Korean Agency for Digital Opportunity and Promotion; NE: Norepinephrine

\section{Acknowledgements}

The authors are grateful to Mr. Jon Mann for his editorial assistance during preparation of the manuscript.

\section{Authors' contributions}

N.K. conceived and designed the study and drafted the manuscript. I.D.K. was involved in participant recruitment, data collection, and theoretical interpretation of the results. M.J.K and T.L.H. provided significant input on the content of the manuscript. H.K. contributed to the acquisition and analysis of data. All authors read and approved the final manuscript.

\section{Funding}

This research was supported by the Basic Science Research Program through the National Research Foundation of Korea (NRF) and was funded by the Ministry of Education, Science and Technology (NRF-2012R1A1A4A01012884). NRF had no role in the study design; data collection, analysis, or interpretation; writing the manuscript; or the decision to submit the paper for publication.

\section{Availability of data and materials}

The datasets used and/or analyzed during the current study are available only upon reasonable request and after compliance with the policies and procedures of the Basic Science Research Program through the National Research Foundation of Korea and the Ministry of Education, Science and Technology (NRF) for data sharing.

\section{Ethics approval and consent to participate}

This study was approved by the Institutional Review Board of Yonsei University Wonju College of Medicine with reference number of YWMR-12-0015. We obtained written informed consent from each participant and his legal guardian. Participation was voluntary, and Participants could withdraw at any time from the study.

\section{Consent for publication}

Not applicable.

\section{Competing interests}

The authors declare no conflict of interest.

\section{Author details}

${ }^{1}$ Keimyung University College of Nursing, Daegu, South Korea. ${ }^{2}$ University of Illinois at Chicago, College of Nursing, Chicago, IL, USA. ${ }^{3}$ Columbia University School of Nursing and Department of Psychiatry, Columbia University Irving Medical Center, New York City, NY, USA. ${ }^{4}$ Department of Nursing, Daekyeung University, Daegu, South Korea. ${ }^{5}$ Department of Physiology, Yonsei University, Wonju College of Medicine, Wonju, Gangwon-Do 26426, Republic of Korea.

Received: 26 July 2019 Accepted: 4 June 2020

Published online: 30 June 2020

\section{References}

1. American Psychiatric Association. Diagnostic and statistical manual of mental disorders (DSM-5 ${ }^{\circledR}$ ). Arlington, VA: American Psychiatric Publishing; 2013.

2. World Health Organization (WHO). (2019). ICD-11 for Mortality and Morbidity Statistics. Retrieved from: https://icd.who.int/browse11/l-/en\#/ http://id.who.int/icd/entity/ 1448597234.

3. Pontes HM, Király O, Demetrovics Z, Griffiths MD. The conceptualisation and measurement of DSM-5 internet gaming disorder: the development of the IGD-20 test. PLoS One. 2014;9(10):e110137.

4. Aarseth E, Bean AM, Boonen H, Carras MC, Coulson M, Das D, Deleuze J, et al. Scholars' open debate paper on the World Health Organization ICD-11 gaming disorder proposal. J Behav Addict. 2017;6:267-70.
5. Dong G, Potenza MN. A cognitive-behavioral model of internet gaming disorder: theoretical underpinnings and clinical implications. J Psychiatr Res. 2014;58:7-11.

6. Jo YS, Bhang SY, Choi JS, Lee HK, Lee SY, Kweon YS. Clinical characteristics of diagnosis for internet gaming disorder: comparison of DSM-5 IGD and ICD-11 GD diagnosis. J Clin Med. 2019:8:945.

7. Kuss DJ, Griffiths MD, Pontes HM. Chaos and confusion in DSM-5 diagnosis of internet gaming disorder: issues, concerns, and recommendations for clarity in the field. J Behav Addict. 2017;6:103-9.

8. Rumpf HJ, Achab S, Billieux J, Bowden-Jones H, Carragher N, Demetrovics Z, et al. Including gaming disorder in the ICD-11: the need to do so from a clinical and public health perspective. J Behav Addict. 2018;7:556-61.

9. van Rooij AJ, Ferguson CJ, van de Mheen D, Schoenmakers TM. Time to abandon internet addiction? Predicting problematic internet, game, and social media use from psychosocial well-being and application use. Clin Neuropsychiatry. 2017;14:113-21.

10. Korea Creative Content Agency. A meta-analysis study on game and immersion research. KOCCA: Jeollanam-do; 2019.

11. Weinstein A, Lejoyeux M. New developments on the neurobiological and pharmaco-genetic mechanisms underlying internet and videogame addiction. Am J Addict. 2015;24:117-25.

12. Kuss DJ, Griffiths MD. Internet and gaming addiction: a systematic literature review of neuroimaging studies. Brain Science. 2012;2:347-74.

13. Kuss DJ. Internet gaming addiction: current perspectives. Psychol Res Behav Manag. 2013;6:125-37.

14. Weinstein A, Lejoyeux M. Internet addiction or excessive internet use. Am J Drug Alcohol Abuse. 2010;36:277-83.

15. Kwon JH, Chung CS, Lee J. The effects of escape from self and interpersonal relationship on the pathological use of internet games. Community Ment Health J. 2011:47:113-21.

16. Deci EL, Ryan RM. A motivational approach to self: Integration in personality. In: Perspectives on motivation. Volume 38, edn. Edited by Deinstbier RA; 1991: 237-288,

17. Ryan RM, Rigby CS, Przybylski A. The motivational pull of video games: a self-determination theory approach. Motiv Emot. 2006;30:347-63.

18. Sherry JL, Lucas K, Greenberg BS, Lachlan K. Video game uses and gratifications as predictors of use and game preference. In: Playing video games: Motives, responses, and consequences. Volume 24, edn. Edited by Vorderer P, Bryant J; 2006: 213-24.

19. Yee N. Motivations for play in online games. CyberPsychol Behav. 2006;9: 772-5.

20. Hilgard J, Engelhardt CR, Bartholow BD. Individual differences in motives, preferences, and pathology in video games: the gaming attitudes, motives, and experiences scales (GAMES). Front Psychol. 2013;4:608.

21. Demetrovics Z, Urbán R, Nagygyörgy K, Farkas J, Zilahy D, Mervó B, Reindl A Ágoston C, Kertész A, Harmath E. Why do you play? The development of the motives for online gaming questionnaire (MOGQ). Behav Res Methods. 2011:43:814-25.

22. Kuss DJ, Louws J, Wiers RW. Online gaming addiction? Motives predict addictive play behavior in massively multiplayer online role-playing games. Cyberpsychol Behav Soc Netw. 2012;15:480-5.

23. Caplan S, Williams D, Yee N. Problematic internet use and psychosocial wellbeing among MMO players. Comput Human Behav. 2009:25:1312-9.

24. Zanetta Dauriat F, Zermatten A, Billieux J, Thorens G, Bondolfi G, Zullino D, Khazaal Y. Motivations to play specifically predict excessive involvement in massively multiplayer online role-playing games: evidence from an online survey. Eur Addict Res. 2011;17:185-9.

25. Fuster H, Chamarro A, Carbonell X, Vallerand RJ. Relationship between passion and motivation for gaming in players of massively multiplayer online role-playing games. Cyberpsychol Behav Soc Netw. 2014;17:292-7.

26. Fuster H, Oberst U, Griffiths M, Carbonell X, Chamarro A, Talarn A. Psychological motivation in online role-playing games: a study of Spanish world of Warcraft players. Anales De Psicologia. 2012;28:274-80.

27. Kneer J, Glock S. Escaping in digital games: the relationship between playing motives and addictive tendencies in males. Comput Human Behav. 2013;29:1415-20.

28. Kneer J, Rieger D. Problematic game play: the diagnostic value of playing motives, passion, and playing time in men. Behav Sci (Basel). 2015:5:203-13.

29. Park J, Song $Y$, Teng $\mathrm{Cl}$. Exploring the links between personality traits and motivations to play online games. Cyberpsychol Behav Soc Netw. 2011:14: 747-51. 
30. Graham LT, Gosling SD. Personality profiles associated with different motivations for playing world of Warcraft. Cyberpsychol Behav Soc Netw. 2013;16:189-93.

31. Coyne SM, Dyer WJ, Densley R, Money NM, Day RD, Harper JM. Physiological indicators of pathologic video game use in adolescence. J Adolesc Health. 2015;56:307-13.

32. Hebert S, Beland R, Dionne-Fournelle O, Crete M, Lupien SJ. Physiological stress response to video-game playing: the contribution of built-in music. Life Sci. 2005;76:2371-80.

33. Ivarsson $M$, Anderson $M$, Akerstedt $T$, Lindblad F. Playing a violent television game affects heart rate variability. Acta Paediatr. 2009;98:166-72.

34. Ivarsson M, Anderson M, Akerstedt $T$, Lindblad $F$. The effect of violent and nonviolent video games on heart rate variability, sleep, and emotions in adolescents with different violent gaming habits. Psychosom Med. 2013;75: 390-6.

35. Lin PC, Kuo SY, Lee PH, Sheen TC, Chen SR. Effects of internet addiction on heart rate variability in school-aged children. J Cardiovasc Nurs. 2014;29: 493-8.

36. Kim N, Hughes TL, Park CG, Quinn L, Kong ID. Resting-state peripheral catecholamine and anxiety levels in Korean male adolescents with internet game addiction. Cyberpsychol Behav Soc Netw. 2016a;19:202-8.

37. Zhang HX, Jiang WQ, Lin ZG, Du YS, Vance A. Comparison of psychological symptoms and serum levels of neurotransmitters in Shanghai adolescents with and without internet addiction disorder: a case-control study. PLoS One. 2013;8:e63089.

38. de Kloet ER, Joels M, Holsboer F. Stress and the brain: from adaptation to disease. Nat Rev Neurosci. 2005;6:463-75.

39. Foss B, Dyrstad SM. Stress in obesity: cause or consequence? Med Hypotheses. 2011;77:7-10.

40. Schwabe L, Dickinson A, Wolf OT. Stress, habits, and drug addiction: a psychoneuroendocrinological perspective. Exp Clin Psychopharmacol. 2011; 19:53-63.

41. Kim EH, Kim NH. Comparison of stress level and HPA axis activity of internet game addiction vs. non-addiction in adolescents. J Korean Biol Nurs Sci. 2013;15:173-83.

42. Kim N, Hughes TL, Park CG, Quinn L, Kong ID. Altered autonomic functions and distressed personality traits in male adolescents with internet gaming addiction. Cyberpsychol Behav Soc Netw. 2016b;19:667-73.

43. Faul F, Erdfelder E, Buchner A, Lang A-G. Statistical power analyses using $G^{*}$ power 3.1: tests for correlation and regression analyses. Behav Res Methods. 2009:41:1149-60.

44. Rehbein F, Kleimann M, Mossle T. Prevalence and risk factors of video game dependency in adolescence: results of a German nationwide survey. Cyberpsychol Behav Soc Netw. 2010;13:269-77.

45. Korean Agency for Digital Opportunity and Promotion (KADO). A study of the development of internet game addiction scale for children and adolescents. Accessed July 01 2012. http://www.iapc.or.kr/dia/survey/ addDiaSurveyNew.do?dia_type_cd=GAYS

46. Young KS. Internet addiction: the emergence of a new clinical disorder. In: Paper presented at the 104th annual convention of the American Psychological Association. Toronto: Canada; 1996.

47. Wan CS, Chiou WB. Why are adolescents addicted to online gaming? An interview study in Taiwan. CyberPsychol Behav. 2006:9:762-6.

48. Dickinson A. Actions and habits: the development of behavioural autonomy. Philosophical Transactions of the Royal Society of London B: Biological Sciences. 1985;308:67-78.

49. Heyes C, Dickinson A. The intentionality of animal action. Mind Lang. 1990;5: 87-103.

50. Peeters M, Wiers RW, Monshouwer $K$, van de Schoot $R$, Janssen $T$, Vollebergh WA. Automatic processes in at-risk adolescents: the role of alcohol-approach tendencies and response inhibition in drinking behavior. Addiction. 2012;107:1939-46.

51. Wiers RW, Bartholow BD, van den Wildenberg E, Thush C, Engels RC, Sher KJ, Grenard J, Ames SL, Stacy AW. Automatic and controlled processes and the development of addictive behaviors in adolescents: a review and a model. Pharmacol Biochem Behav. 2007:86:263-83.

52. Adams CD, Dickinson A. Instrumental responding following reinforcer devaluation. Q J Exp Psychol. 1981;33:109-21.

53. Adams CD. Variations in the sensitivity of instrumental responding to reinforcer devaluation. Quarterly Journal of Experimental Psychology Section B-Comparative and Physiological Psychology. 1982;34:77-98.
54. Balleine BW, Dickinson A. The role of incentive learning in instrumental outcome revaluation by sensory-specific satiety. Anim Learn Behav. 1998;26: 46-59.

55. Watson P, de Wit S, Hommel B, Wiers RW. Motivational mechanisms and outcome expectancies underlying the approach bias toward addictive substances. Front Psychol. 2012;3:440.

56. Wood W, Neal DT. A new look at habits and the habit-goal interface. Psychol Rev. 2007;114:843-63.

57. Everitt BJ, Robbins TW. Neural systems of reinforcement for drug addiction: from actions to habits to compulsion. Nat Neurosci. 2005;8:1481-9.

58. Kuss DJ, Griffiths MD. Online gaming addiction in children and adolescents: a review of empirical research. J Behav Addict. 2012;1:3-22.

59. Volkow ND, Fowler JS, Wang GJ. The addicted human brain: insights from imaging studies. J Clin Invest. 2003;111:1444-51.

60. Schwabe L, Hoffken O, Tegenthoff M, Wolf OT. Preventing the stressinduced shift from goal-directed to habit action with a beta-adrenergic antagonist. J Neurosci. 2011;31:17317-25.

61. Schwabe L, Tegenthoff M, Hoffken O, Wolf OT. Concurrent glucocorticoid and noradrenergic activity shifts instrumental behavior from goal-directed to habitual control. J Neurosci. 2010;30:8190-6.

62. Schwabe L, Tegenthoff M, Hoffken O, Wolf OT. Simultaneous glucocorticoid and noradrenergic activity disrupts the neural basis of goal-directed action in the human brain. J Neurosci. 2012;32:10146-55.

63. Schwabe L, Wolf OT. Stress prompts habit behavior in humans. J Neurosci. 2009;29:7191-8

64. Sinha R. Chronic stress, drug use, and vulnerability to addiction. Ann N Y Acad Sci. 2008;1141:105-30.

65. Fox HC, Hong Kl, Siedlarz KM, Bergquist K, Anderson G, Kreek MJ, Sinha R. Sex-specific dissociations in autonomic and HPA responses to stress and cues in alcohol-dependent patients with cocaine abuse. Alcohol Alcohol. 2009:44:575-85

66. Blaine SK, Sinha R. Alcohol, stress, and glucocorticoids: from risk to dependence and relapse in alcohol use disorders. Neuropharmacology. 2017;122:136-147

67. Li Y., Ramoz N., Derrington E, \& Dreher, J.-C. (2020). Hormonal responses in gambling versus alcohol abuse: a review of human studies. Prog NeuroPsychopharmacol biol psychiatry. 2020;100:109880.

68. Geisel O, Panneck P, Hellweg R, Wiedemann K, Müller CA. Hypothalamicpituitary-adrenal axis activity in patients with pathological gambling and internet use disorder. Psychiatry Res. 2015;226:97-102.

69. Li Y, Sescousse G, Dreher J-C. Endogenous cortisol levels are associated with an imbalanced striatal sensitivity to monetary versus non-monetary cues in pathological gamblers. Front behav neurosci. 2014;8:83.

\section{Publisher's Note}

Springer Nature remains neutral with regard to jurisdictional claims in published maps and institutional affiliations.

Ready to submit your research? Choose BMC and benefit from:

- fast, convenient online submission

- thorough peer review by experienced researchers in your field

- rapid publication on acceptance

- support for research data, including large and complex data types

- gold Open Access which fosters wider collaboration and increased citations

- maximum visibility for your research: over $100 \mathrm{M}$ website views per year

At BMC, research is always in progress.

Learn more biomedcentral.com/submission 